\title{
Secondary Interactions in Gold(I) Complexes with Thione Ligands, 4. Three Further Salts of the Bis(imidazolidine-2-thione)gold(I) Cation [1,2]
}

\author{
Steffi Friedrichs and Peter G. Jones \\ Institut für Anorganische und Analytische Chemie, Technische Universität Braunschweig, \\ Postfach 3329, D-38023 Braunschweig, Germany \\ Reprint requests to Prof. Dr. P.G. Jones. E-mail: p.jones@tu-bs.de \\ Z. Naturforsch. 61b, 1391 - 1400 (2006); received August 29, 2006
}

Dedicated to Dr. José-Antonio Abad on the occasion of his retirement

Three structures of the form bis(imidazolidine-2-thione)gold(I) disulfonylamide [disulfonylamide = benzene-1,2-di(sulfonyl)amide (1), di(4-chlorobenzenesulfonyl)amide (2), di(4-iodobenzenesulfonyl)amide (3)] were determined. Compound $\mathbf{3}$ crystallizes with four independent formula units. The cations in $\mathbf{1}$ and $\mathbf{3}$ show an antiperiplanar conformation about the $\mathrm{S} \cdots \mathrm{S}$ axis, whereas the corresponding torsion angle in $\mathbf{2}$ is $72^{\circ}$. The packing in $\mathbf{1}$ consists of linked ribbons in which the $\mathrm{NH}$ groups of neighbouring cations are bridged by $\mathrm{O}-\mathrm{S}-\mathrm{O}$ groups of the anions. Compound 2 exhibits a complex layer structure in which several multi-centre hydrogen bonds are observed. The structural subunits of compound $\mathbf{3}$ involve an alternating anion-cation chain for two of the cations and inversionsymmetric anion-cation dimers for the other two cations. Short C-H $\cdots$ Au contacts (shortest $\mathrm{H} \cdots \mathrm{Au}$ $2.63 \AA$ in 2 ) contribute to the packing of compounds $\mathbf{2}$ and $\mathbf{3}$.

Key words: Thiones, Disulfonylamides, Gold, Hydrogen Bonds

\section{Introduction}

Our previous studies of secondary interactions in gold(I) complexes of heterocyclic ligands bearing a thione group have involved chloride [3], camphorsulfonate [4] and di(methanesulfonyl)amide (DMS) [1] salts of the complex cations $\left[\mathrm{L}_{2} \mathrm{Au}\right]^{+}$with $\mathrm{L}=$ imidazolidine-2-thione ("ethylenethiourea", etu), 1-methyl-imidazolidine-2-thione and thiazolidine-2thione. The earlier publications may be consulted for a summary of results. Ideally, one would like to obtain structures for all possible combinations of thione ligands and counteranions. In practice, many potential candidates either cannot be prepared in a pure state, refuse to form single crystals or present severely disordered structures. For this reason, we reverse our previous practice of varying the cation for a constant anion and present here three further salts of the cation bis(imidazolidine-2-thione)gold(I), $\left[(\mathrm{etu})_{2} \mathrm{Au}\right]^{+} \mathrm{X}^{-}$, with various disulfonylamide anions, namely $\mathrm{X}=$ benzene-1,2-di(sulfonyl)amide (1), di(4chlorobenzenesulfonyl)amide (2), and di(4-iodobenzenesulfonyl)amide (3) (Scheme 1). Reference will be made to the previously determined structures of the same cation, namely the chloride, chloride hydrate [3], DMS [1] and camphorsulfonate [4] salts.

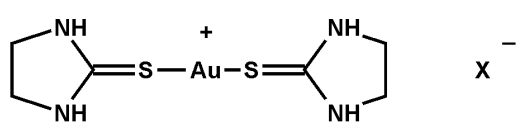<smiles>[X]=C1NS(=O)(=O)c2ccccc21</smiles><smiles>[X]c1ccc(S(=O)(=O)NS(=O)(=O)c2ccc([Hg])cc2)cc1</smiles>

Scheme 1.

\section{Discussion}

\section{General aspects}

All three compounds crystallize solvent-free (Table 1). Compound 1 (Fig. 1) is non-centrosymmetric 


\begin{tabular}{|c|c|c|c|}
\hline Compound & 1 & 2 & 3 \\
\hline Formula & $\mathrm{C}_{12} \mathrm{H}_{16} \mathrm{AuN}_{5} \mathrm{O}_{4} \mathrm{~S}_{4}$ & $\mathrm{C}_{18} \mathrm{H}_{20} \mathrm{AuCl}_{2} \mathrm{~N}_{5} \mathrm{O}_{4} \mathrm{~S}_{4}$ & $\mathrm{C}_{18} \mathrm{H}_{20} \mathrm{AuI}_{2} \mathrm{~N}_{5} \mathrm{O}_{4} \mathrm{~S}_{4}$ \\
\hline$M_{\mathrm{r}}\left[\mathrm{g} \mathrm{mol}^{-1}\right]$ & 619.50 & 766.50 & 949.40 \\
\hline Crystal system & orthorhombic & monoclinic & triclinic \\
\hline Space group & $\operatorname{Pna}_{1}$ & $P 2_{1} / n$ & $P \overline{1}$ \\
\hline$a[\AA]$ & $18.889(3)$ & $7.7821(8)$ & $15.541(3)$ \\
\hline$b[\AA]$ & $7.3727(10)$ & $23.813(2)$ & $17.735(3)$ \\
\hline$c[\AA]$ & $13.430(2)$ & $13.3609(14)$ & $20.053(4)$ \\
\hline$\alpha[\mathrm{deg}]$ & 90 & 90 & $88.74(2)$ \\
\hline$\beta[\mathrm{deg}]$ & 90 & $97.799(8)$ & $70.66(2)$ \\
\hline$\gamma[\mathrm{deg}]$ & 90 & 90 & $89.97(2)$ \\
\hline$V\left[\AA^{3}\right]$ & 1870.3 & 2453.0 & 5213.8 \\
\hline$Z$ & 4 & 4 & 8 \\
\hline$F(000)$ & 1192 & 1488 & 3552 \\
\hline Crystal habit & colourless plate & colourless prism & colourless tablet \\
\hline Crystal size $\left[\mathrm{mm}^{3}\right]$ & $0.45 \times 0.24 \times 0.03$ & $0.36 \times 0.28 \times 0.24$ & $0.28 \times 0.20 \times 0.12$ \\
\hline$D_{x}\left[\mathrm{~g} \mathrm{~cm}^{-3}\right]$ & 2.200 & 2.075 & 2.419 \\
\hline $2 \theta_{\max }[\mathrm{deg}]$ & 56.6 & 50 & 50 \\
\hline$\mu\left[\mathrm{mm}^{-1}\right]$ & 8.34 & 6.59 & 8.37 \\
\hline Temperature $[\mathrm{K}]$ & 163 & 173 & 173 \\
\hline Absorption correction & multiple scans (SADABS) & $\psi$ scans & $\psi$ scans \\
\hline$T_{\min } / T_{\max }$ & $0.99 / 0.37$ & $0.67 / 0.58$ & $0.97 / 0.48$ \\
\hline Measured reflections & 12150 & 5596 & 18370 \\
\hline Independent reflections & 4552 & 4314 & 18235 \\
\hline$R_{\text {int }}$ & 0.083 & 0.024 & 0.059 \\
\hline Restraints & 199 & 4 & 2118 \\
\hline Parameters & 236 & 320 & 1261 \\
\hline$S$ & 0.96 & 0.90 & 0.69 \\
\hline$R 1\left[F^{2} \geq 2 \sigma\left(F^{2}\right)\right]$ & 0.042 & 0.024 & 0.048 \\
\hline$w R 2\left(F^{2}\right.$, all refl. $)$ & 0.091 & 0.049 & 0.078 \\
\hline$\Delta \rho_{\min } / \Delta \rho_{\max }\left[\mathrm{e} \AA^{-3}\right]$ & $1.7 /-2.1$ & $0.96 /-0.49$ & $1.13 /-1.02$ \\
\hline
\end{tabular}

Table 1. Crystallographic data collection, solution and refinement details for $\mathbf{1 ,} \mathbf{2}$ and $\mathbf{3}$.

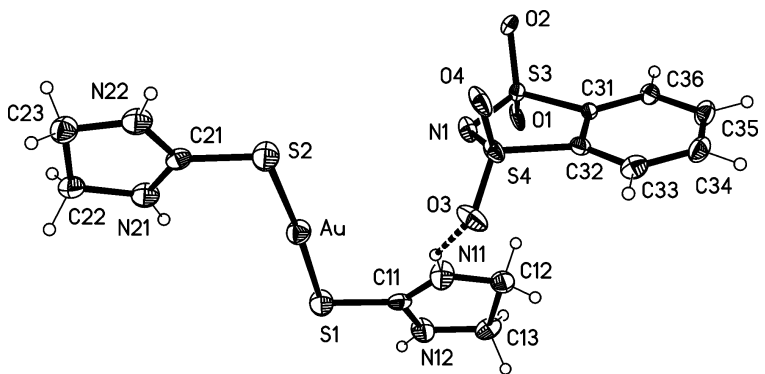

Fig. 1. Bis(imidazolidine-2-thione)gold(I) benzene-1,2-di(sulfonyl)amide, 1, asymmetric unit with numbering scheme. Thermal ellipsoids are shown with $50 \%$ probability. Hydrogen radii are arbitrary. The dashed line represents a classical hydrogen bond.

but racemically twinned; compound $\mathbf{3}$ crystallizes with four independent formula units in the asymmetric unit (Fig. 3 shows one formula unit). Accordingly, these two structures are less precisely determined than that of compound 2 (Fig. 2). Summaries of bond lengths, bond angles and torsion angles are presented in Tables 2-4.

All $\left[(\mathrm{etu})_{2} \mathrm{Au}\right]^{+}$cations display bond lengths and angles broadly as expected, e. $g$. S-Au-S bond angles
Table 2. Bond lengths, bond angles and torsion angles (A, deg) for compound $\mathbf{1}$.

\begin{tabular}{llll}
\hline $\mathrm{Au}-\mathrm{S}(1)$ & $2.282(2)$ & $\mathrm{Au}-\mathrm{S}(2)$ & $2.283(2)$ \\
$\mathrm{S}(1)-\mathrm{C}(11)$ & $1.721(7)$ & $\mathrm{S}(2)-\mathrm{C}(21)$ & $1.732(7)$ \\
$\mathrm{N}(1)-\mathrm{S}(4)$ & $1.586(6)$ & $\mathrm{N}(1)-\mathrm{S}(3)$ & $1.590(6)$ \\
$\mathrm{S}(3)-\mathrm{O}(2)$ & $1.438(5)$ & $\mathrm{S}(3)-\mathrm{O}(1)$ & $1.441(5)$ \\
$\mathrm{S}(3)-\mathrm{C}(31)$ & $1.771(6)$ & $\mathrm{S}(4)-\mathrm{O}(3)$ & $1.439(5)$ \\
$\mathrm{S}(4)-\mathrm{O}(4)$ & $1.445(5)$ & $\mathrm{S}(4)-\mathrm{C}(32)$ & $1.776(6)$ \\
$\mathrm{S}(1)-\mathrm{Au}-\mathrm{S}(2)$ & $175.86(10)$ & $\mathrm{C}(11)-\mathrm{S}(1)-\mathrm{Au}$ & $105.9(2)$ \\
$\mathrm{C}(21)-\mathrm{S}(2)-\mathrm{Au}$ & $103.7(2)$ & $\mathrm{S}(4)-\mathrm{N}(1)-\mathrm{S}(3)$ & $114.5(4)$
\end{tabular}

$\mathrm{C}(11)-\mathrm{S}(1) \cdots \mathrm{S}(2)-\mathrm{C}(21) \quad 175.8(4)$

$\mathrm{Au}-\mathrm{S}(1)-\mathrm{C}(11)-\mathrm{N}(11) \quad 8.7(8) \quad \mathrm{Au}-\mathrm{S}(2)-\mathrm{C}(21)-\mathrm{N}(21)-3.9(7)$ $\begin{array}{llll}\mathrm{S}(4)-\mathrm{N}(1)-\mathrm{S}(3)-\mathrm{O}(2) & -97.7(4) & \mathrm{S}(4)-\mathrm{N}(1)-\mathrm{S}(3)-\mathrm{O}(1) & 133.6(4)\end{array}$ $\mathrm{S}(3)-\mathrm{N}(1)-\mathrm{S}(4)-\mathrm{O}(3) \quad-138.7(4) \quad \mathrm{S}(3)-\mathrm{N}(1)-\mathrm{S}(4)-\mathrm{O}(4) \quad 91.5(4)$

close to linearity, with values of $172-178^{\circ}, \mathrm{Au}-\mathrm{S}$ bond lengths in the range $2.27-2.30 \AA$, or the angles at sulfur, $101-108^{\circ}$. Individual values may be taken from Tables 2-4 or the Supplementary Material.

The benzene-1,2-di(sulfonyl)amide anion in $\mathbf{1}$ displays the usual structural features [5], except that the sulfur atom S4 lies as much as $0.23 \AA$ out of the plane of the six-membered ring (to the opposite side from the nitrogen atom, which lies $0.10 \AA$ out of the plane). The 


\begin{tabular}{llll}
\hline $\mathrm{Au}-\mathrm{S}(2)$ & $2.2704(12)$ & $\mathrm{Au}-\mathrm{S}(1)$ & $2.2808(11)$ \\
$\mathrm{S}(1)-\mathrm{C}(11)$ & $1.724(5)$ & $\mathrm{S}(2)-\mathrm{C}(21)$ & $1.719(5)$ \\
$\mathrm{N}(1)-\mathrm{S}(4)$ & $1.598(4)$ & $\mathrm{N}(1)-\mathrm{S}(3)$ & $1.613(4)$ \\
$\mathrm{S}(3)-\mathrm{O}(1)$ & $1.435(4)$ & $\mathrm{S}(3)-\mathrm{O}(2)$ & $1.443(3)$ \\
$\mathrm{S}(3)-\mathrm{C}(31)$ & $1.766(5)$ & $\mathrm{S}(4)-\mathrm{O}(4)$ & $1.441(3)$ \\
$\mathrm{S}(4)-\mathrm{O}(3)$ & $1.445(3)$ & $\mathrm{S}(4)-\mathrm{C}(41)$ & $1.773(4)$ \\
$\mathrm{S}(2)-\mathrm{Au}-\mathrm{S}(1)$ & $171.96(5)$ & $\mathrm{C}(11)-\mathrm{S}(1)-\mathrm{Au}$ & $103.86(15)$ \\
$\mathrm{C}(21)-\mathrm{S}(2)-\mathrm{Au}$ & $107.97(15)$ & $\mathrm{S}(4)-\mathrm{N}(1)-\mathrm{S}(3)$ & $123.7(2)$ \\
$\mathrm{C}(11)-\mathrm{S}(1) \cdots \mathrm{S}(2)-\mathrm{C}(21)$ & $72.5(2)$ & $\mathrm{Au}-\mathrm{S}(1)-\mathrm{C}(11)-\mathrm{N}(11)$ & $-20.0(4)$ \\
$\mathrm{Au}-\mathrm{S}(2)-\mathrm{C}(21)-\mathrm{N}(21)$ & $-20.7(5)$ & $\mathrm{C}(31)-\mathrm{S}(3) \cdots \mathrm{S}(4)-\mathrm{C}(41)$ & $5.2(2)$ \\
$\mathrm{S}(4)-\mathrm{N}(1)-\mathrm{S}(3)-\mathrm{O}(1)$ & $-166.9(3)$ & $\mathrm{S}(4)-\mathrm{N}(1)-\mathrm{S}(3)-\mathrm{O}(2)$ & $-38.0(3)$ \\
$\mathrm{S}(3)-\mathrm{N}(1)-\mathrm{S}(4)-\mathrm{O}(4)$ & $43.7(3)$ & $\mathrm{S}(3)-\mathrm{N}(1)-\mathrm{S}(4)-\mathrm{O}(3)$ & $170.7(2)$ \\
$\mathrm{O}(2)-\mathrm{S}(3)-\mathrm{C}(31)-\mathrm{C}(32)$ & $22.1(4)$ & $\mathrm{O}(4)-\mathrm{S}(4)-\mathrm{C}(41)-\mathrm{C}(42)$ & $12.2(4)$ \\
\hline
\end{tabular}

Table 3. Bond lengths, bond angles and torsion angles ( $\AA$, deg) for compound 2 .

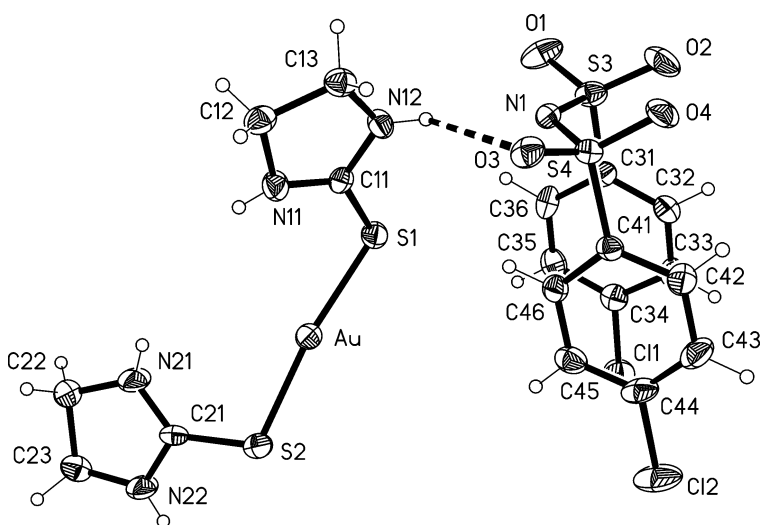

Fig. 2. Bis(imidazolidine-2-thione)gold(I) di(4-chlorobenzenesulfonyl)amide, 2, asymmetric unit with numbering scheme. Thermal ellipsoids are shown with $50 \%$ probability. Hydrogen radii are arbitrary. The dashed line represents a classical hydrogen bond.

$\mathrm{N}-\mathrm{S}-\mathrm{N}-\mathrm{O}$ torsion angles thus differ pairwise (two absolute values of $c a .135^{\circ}$, two of $c a .95^{\circ}$; by convention the odd-numbered oxygen atoms display the larger absolute torsion angles). For a more extensive discussion of the standard geometry, see Ref. [5].

The di(4-halo-benzenesulfonyl)amide anions of compounds $\mathbf{2}$ and $\mathbf{3}$, like their parent disulfonylamines, may in principle display either a folded conformation with local mirror symmetry ("hairpin" form) or an extended conformation with local twofold symmetry. Irrespective of the local symmetry, two of the N-S$\mathrm{N}-\mathrm{O}$ torsion angles are approximately $180^{\circ}$, leading to a $W$-shaped $\mathrm{O}-\mathrm{S}-\mathrm{N}-\mathrm{S}-\mathrm{O}$ sequence; these antiperiplanar oxygen atoms are assigned the odd numbers, whereas the even-numbered oxygens are involved in synclinal $\mathrm{S}=\mathrm{O}$ bonds. Each $\mathrm{C}(\mathrm{x} 1)-\mathrm{C}(\mathrm{x} 2)$ ring bond is synperiplanar to the adjacent $\mathrm{S}=\mathrm{O}(s c)$ bond. For a more complete description of the standard geometry, see Refs. [6,7]. Here, all anions in $\mathbf{2}$ and $\mathbf{3}$ are folded, with intercentroid distances $(\AA)$ of 3.66 for 2

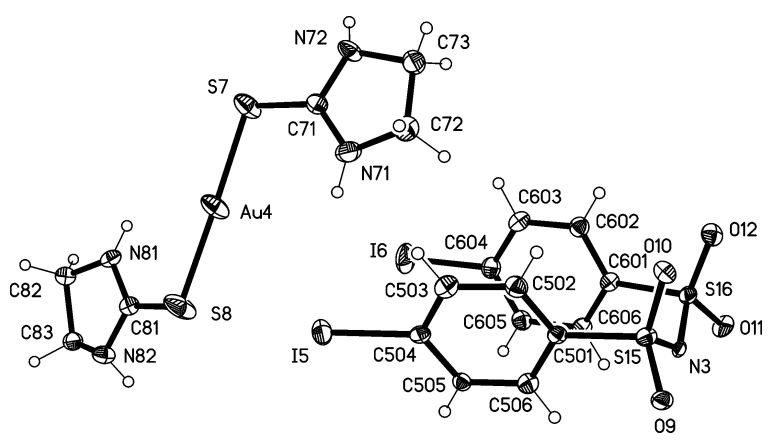

Fig. 3. Bis(imidazolidine-2-thione)gold(I) di(4-iodobenzenesulfonyl)amide, $\mathbf{3}$, one of four formula units with numbering scheme. Thermal ellipsoids are shown with $30 \%$ probability. Hydrogen radii are arbitrary. The arbitrarily defined "first" cation is numbered with $A u 1, \mathrm{~S} 1, \mathrm{~S} 2, \mathrm{C} 1 \mathrm{x}, \mathrm{C} 2 \mathrm{x}, \mathrm{N} 1 \mathrm{x}, \mathrm{N} 2 \mathrm{x}$, the second as Au2-C43, etc. The first anion is numbered with S11, S12, N1, O1-4, C10x, C20x, I1 and I2, the second as S13-I4, etc. Correspondingly, this Fig. shows the fourth formula unit.

and 3.58, 3.63, 3.71, 3.62 for the four anions of $\mathbf{3}$, corresponding interplanar angles $9.2(2)^{\circ} ; 12.9(3), 14.1(3)$, $19.0(3), 12.8(4)^{\circ}$, and absolute C-S $\cdots \mathrm{S}-\mathrm{C}$ torsion angles $5.2(2)^{\circ} ; 1.9(5), 6.2(5), 3.7(5), 4.5(5)^{\circ}$. The validity of the local symmetry can be expressed by $\Delta \tau_{\mathrm{SN}}$, the average difference between related pairs of absolute torsion angles about the $\mathrm{S}-\mathrm{N}$ bonds, which is $5.9^{\circ}$ for 2 and $1.3,6.3,4.6,5.4^{\circ}$ for 3 . The parent amines display the extended conformation for the chloro [7] and iodo [8] derivatives, although both forms are known, as separate polymorphs, for the bromo compound [6].

Our previous publications $[1,3,4]$ established that the most relevant structural degree of freedom in the bis(thione)gold(I) cations is the torsion angle C$\mathrm{S} \cdot \mathrm{S}-\mathrm{C}$. For the $\left[(\mathrm{etu})_{2} \mathrm{Au}\right]$ cation, the chloride hydrate displays the unfavourable cis (synperiplanar) conformation, with a torsion angle of $-20^{\circ}$, because of hydrogen bonding from both cis $\mathrm{NH}$ groups of 


\begin{tabular}{|c|c|c|c|}
\hline$\overline{\mathrm{Au}(1)-\mathrm{S}(1)}$ & $2.297(4)$ & $\mathrm{S}(15)-\mathrm{N}(3)$ & $1.602(11)$ \\
\hline $\mathrm{Au}(1)-\mathrm{S}(2)$ & $2.297(4)$ & $S(15)-C(501)$ & $1.768(11)$ \\
\hline$S(1)-C(11)$ & $1.696(10)$ & $\mathrm{S}(16)-\mathrm{O}(11)$ & $1.415(9)$ \\
\hline$S(2)-C(21)$ & $1.714(10)$ & $\mathrm{S}(16)-\mathrm{O}(12)$ & $1.426(8)$ \\
\hline $\mathrm{Au}(2)-\mathrm{S}(4)$ & $2.276(4)$ & $\mathrm{S}(16)-\mathrm{N}(3)$ & $1.601(10)$ \\
\hline $\mathrm{Au}(2)-\mathrm{S}(3)$ & $2.296(4)$ & $S(16)-C(601)$ & $1.794(11)$ \\
\hline$S(3)-C(31)$ & $1.714(10)$ & $\mathrm{S}(17)-\mathrm{O}(14)$ & $1.433(9)$ \\
\hline$S(4)-C(41)$ & $1.737(10)$ & $\mathrm{S}(17)-\mathrm{O}(13)$ & $1.437(8)$ \\
\hline $\mathrm{Au}(3)-\mathrm{S}(5)$ & $2.284(4)$ & $S(17)-N(4)$ & $1.587(11)$ \\
\hline $\mathrm{Au}(3)-\mathrm{S}(6)$ & $2.289(4)$ & $S(17)-C(701)$ & $1.772(11)$ \\
\hline$S(5)-C(51)$ & $1.702(10)$ & $\mathrm{S}(18)-\mathrm{O}(16)$ & $1.427(9)$ \\
\hline$S(6)-C(61)$ & $1.708(10)$ & $\mathrm{S}(18)-\mathrm{O}(15)$ & $1.430(9)$ \\
\hline $\mathrm{Au}(4)-\mathrm{S}(7)$ & $2.290(4)$ & $\mathrm{S}(18)-\mathrm{N}(4)$ & $1.593(10)$ \\
\hline $\mathrm{Au}(4)-\mathrm{S}(8)$ & $2.298(4)$ & $S(18)-C(801)$ & $1.739(12)$ \\
\hline$S(7)-C(71)$ & $1.721(10)$ & & \\
\hline$S(8)-C(81)$ & $1.728(10)$ & & \\
\hline $\mathrm{S}(11)-\mathrm{O}(2)$ & $1.427(8)$ & $S(1)-A u(1)-S(2)$ & $176.42(15)$ \\
\hline $\mathrm{S}(11)-\mathrm{O}(1)$ & $1.442(8)$ & $\mathrm{C}(11)-\mathrm{S}(1)-\mathrm{Au}(1)$ & $105.3(4)$ \\
\hline $\mathrm{S}(11)-\mathrm{N}(1)$ & $1.597(10)$ & $\mathrm{C}(21)-\mathrm{S}(2)-\mathrm{Au}(1)$ & $104.9(4)$ \\
\hline$S(11)-C(101)$ & $1.760(11)$ & $S(4)-A u(2)-S(3)$ & $177.21(12)$ \\
\hline $\mathrm{S}(12)-\mathrm{O}(3)$ & $1.440(10)$ & $\mathrm{C}(31)-\mathrm{S}(3)-\mathrm{Au}(2)$ & $101.3(4)$ \\
\hline $\mathrm{S}(12)-\mathrm{O}(4)$ & $1.440(8)$ & $\mathrm{C}(41)-\mathrm{S}(4)-\mathrm{Au}(2)$ & $104.9(4)$ \\
\hline $\mathrm{S}(12)-\mathrm{N}(1)$ & $1.616(10)$ & $S(5)-A u(3)-S(6)$ & $175.58(14)$ \\
\hline$S(12)-C(201)$ & $1.753(11)$ & $C(51)-S(5)-A u(3)$ & $101.8(4)$ \\
\hline $\mathrm{S}(13)-\mathrm{O}(5)$ & $1.418(10)$ & $\mathrm{C}(61)-\mathrm{S}(6)-\mathrm{Au}(3)$ & $102.6(4)$ \\
\hline $\mathrm{S}(13)-\mathrm{O}(6)$ & $1.448(8)$ & $S(7)-A u(4)-S(8)$ & $178.39(13)$ \\
\hline $\mathrm{S}(13)-\mathrm{N}(2)$ & $1.620(10)$ & $\mathrm{C}(71)-\mathrm{S}(7)-\mathrm{Au}(4)$ & $105.7(4)$ \\
\hline$S(13)-C(301)$ & $1.776(11)$ & $\mathrm{C}(81)-\mathrm{S}(8)-\mathrm{Au}(4)$ & $105.7(4)$ \\
\hline $\mathrm{S}(14)-\mathrm{O}(8)$ & $1.444(8)$ & $\mathrm{S}(11)-\mathrm{N}(1)-\mathrm{S}(12)$ & 123.1(6) \\
\hline $\mathrm{S}(14)-\mathrm{O}(7)$ & $1.463(8)$ & $S(14)-N(2)-S(13)$ & $124.0(7)$ \\
\hline $\mathrm{S}(14)-\mathrm{N}(2)$ & $1.560(11)$ & $S(16)-N(3)-S(15)$ & $125.3(6)$ \\
\hline$S(14)-C(401)$ & $1.766(11)$ & $S(17)-N(4)-S(18)$ & $123.7(7)$ \\
\hline $\mathrm{S}(15)-\mathrm{O}(9)$ & $1.443(8)$ & & \\
\hline $\mathrm{S}(15)-\mathrm{O}(10)$ & $1.443(8)$ & & \\
\hline$C(31)-S(3) \cdots S(4)-C(41)$ & $-163.4(6)$ & $\mathrm{C}(11)-\mathrm{S}(1) \cdots \mathrm{S}(2)-\mathrm{C}(21)$ & $166.3(7)$ \\
\hline$C(51)-S(5) \cdots S(6)-C(61)$ & $170.2(6)$ & $\mathrm{O}(7)-\mathrm{S}(14)-\mathrm{N}(2)-\mathrm{S}(13)$ & $-177.4(6)$ \\
\hline$C(71)-S(7) \cdots S(8)-C(81)$ & $-163.4(7)$ & $\mathrm{O}(5)-\mathrm{S}(13)-\mathrm{N}(2)-\mathrm{S}(14)$ & $170.6(6)$ \\
\hline $\mathrm{Au}(1)-\mathrm{S}(1)-\mathrm{C}(11)-\mathrm{N}(11)$ & $0.9(13)$ & $\mathrm{O}(6)-\mathrm{S}(13)-\mathrm{N}(2)-\mathrm{S}(14)$ & $41.1(8)$ \\
\hline $\mathrm{Au}(1)-\mathrm{S}(2)-\mathrm{C}(21)-\mathrm{N}(21)$ & $-9.8(14)$ & $\mathrm{O}(11)-\mathrm{S}(16)-\mathrm{N}(3)-\mathrm{S}(15)$ & $173.0(6)$ \\
\hline $\mathrm{Au}(2)-\mathrm{S}(3)-\mathrm{C}(31)-\mathrm{N}(31)$ & $-10.2(12)$ & $\mathrm{O}(12)-\mathrm{S}(16)-\mathrm{N}(3)-\mathrm{S}(15)$ & $43.3(8)$ \\
\hline $\mathrm{Au}(2)-\mathrm{S}(4)-\mathrm{C}(41)-\mathrm{N}(41)$ & $4.8(13)$ & $\mathrm{O}(9)-\mathrm{S}(15)-\mathrm{N}(3)-\mathrm{S}(16)$ & $-168.4(6)$ \\
\hline $\mathrm{Au}(3)-\mathrm{S}(5)-\mathrm{C}(51)-\mathrm{N}(51)$ & $-26.6(13)$ & $\mathrm{O}(10)-\mathrm{S}(15)-\mathrm{N}(3)-\mathrm{S}(16)$ & $-39.4(8)$ \\
\hline $\mathrm{Au}(3)-\mathrm{S}(6)-\mathrm{C}(61)-\mathrm{N}(61)$ & $1.1(13)$ & $\mathrm{O}(14)-\mathrm{S}(17)-\mathrm{N}(4)-\mathrm{S}(18)$ & $47.9(8)$ \\
\hline $\mathrm{Au}(4)-\mathrm{S}(7)-\mathrm{C}(71)-\mathrm{N}(71)$ & $2.4(15)$ & $\mathrm{O}(13)-\mathrm{S}(17)-\mathrm{N}(4)-\mathrm{S}(18)$ & $175.4(6)$ \\
\hline $\mathrm{Au}(4)-\mathrm{S}(8)-\mathrm{C}(81)-\mathrm{N}(81)$ & $-6.3(14)$ & $\mathrm{O}(16)-\mathrm{S}(18)-\mathrm{N}(4)-\mathrm{S}(17)$ & $-41.8(8)$ \\
\hline$C(101)-S(11) \cdots S(12)-C(201)$ & $-1.9(5)$ & $\mathrm{O}(15)-\mathrm{S}(18)-\mathrm{N}(4)-\mathrm{S}(17)$ & $-170.1(7)$ \\
\hline $\mathrm{C}(301)-\mathrm{S}(13) \cdots \mathrm{S}(14)-\mathrm{C}(401)$ & $-6.2(5)$ & $\mathrm{O}(2)-\mathrm{S}(11)-\mathrm{C}(101)-\mathrm{C}(102)$ & $-5.0(9)$ \\
\hline$C(501)-S(15) \cdots S(16)-C(601)$ & $3.7(5)$ & $\mathrm{O}(4)-\mathrm{S}(12)-\mathrm{C}(201)-\mathrm{C}(202)$ & $-16.5(10)$ \\
\hline $\mathrm{C}(701)-\mathrm{S}(17) \cdots \mathrm{S}(18)-\mathrm{C}(801)$ & $4.5(5)$ & $\mathrm{O}(6)-\mathrm{S}(13)-\mathrm{C}(301)-\mathrm{C}(302)$ & $-14.4(9)$ \\
\hline $\mathrm{O}(2)-\mathrm{S}(11)-\mathrm{N}(1)-\mathrm{S}(12)$ & $-44.1(8)$ & $\mathrm{O}(8)-\mathrm{S}(14)-\mathrm{C}(401)-\mathrm{C}(402)$ & $-6.6(9)$ \\
\hline $\mathrm{O}(1)-\mathrm{S}(11)-\mathrm{N}(1)-\mathrm{S}(12)$ & $-172.6(6)$ & $\mathrm{O}(10)-\mathrm{S}(15)-\mathrm{C}(501)-\mathrm{C}(502)$ & $-15.0(9)$ \\
\hline $\mathrm{O}(3)-\mathrm{S}(12)-\mathrm{N}(1)-\mathrm{S}(11)$ & $173.4(6)$ & $\mathrm{O}(12)-\mathrm{S}(16)-\mathrm{C}(601)-\mathrm{C}(602)$ & $-12.9(10)$ \\
\hline $\mathrm{O}(4)-\mathrm{S}(12)-\mathrm{N}(1)-\mathrm{S}(11)$ & $42.3(8)$ & $\mathrm{O}(14)-\mathrm{S}(17)-\mathrm{C}(701)-\mathrm{C}(702)$ & $3.1(10)$ \\
\hline $\mathrm{O}(8)-\mathrm{S}(14)-\mathrm{N}(2)-\mathrm{S}(13)$ & $-50.0(8)$ & $\mathrm{O}(16)-\mathrm{S}(18)-\mathrm{C}(801)-\mathrm{C}(802)$ & $16.4(11)$ \\
\hline
\end{tabular}

Table 4. Bond lengths, bond angles and torsion angles $(\AA, \mathrm{deg})$ for compound $\mathbf{3}$. the same cation to the water molecule. This value relaxes to $-79^{\circ}$ in the anhydrous chloride, where the $\mathrm{NH}$ groups hydrogen bond to the chloride [3]. The other derivatives show no such "intracationic" hydrogen bonding; the camphorsulfonate [4] shows further widened torsion angles of $\pm 111^{\circ}$ in two independent cations, whereas the DMS salt [1] shows a nearly ideal trans (antiperiplanar) conformation $\left(-174^{\circ}\right)$, which, other things being equal, might be expected to be the most stable form. The complex cations in $\mathbf{1}$ and $\mathbf{3}$ show 


\begin{tabular}{llcccc}
\hline & $\mathrm{D}-\mathrm{H} \cdots \mathrm{A}$ & $\mathrm{d}(\mathrm{D}-\mathrm{H})$ & $\mathrm{d}(\mathrm{H} \cdots \mathrm{A})$ & $\mathrm{d}(\mathrm{D} \cdots \mathrm{A})$ & $\angle(\mathrm{DHA})$ \\
\hline$(a)$ & $\mathrm{N}(11)-\mathrm{H}(11) \cdots \mathrm{O}(3)$ & 0.88 & 2.12 & $2.909(8)$ & 149 \\
$(b)$ & $\mathrm{N}(12)-\mathrm{H}(12) \cdots \mathrm{O}(4)^{\# 1}$ & 0.88 & 2.13 & $2.935(8)$ & 151 \\
$(c)$ & $\mathrm{N}(21)-\mathrm{H}(21) \cdots \mathrm{O}(1)^{\# 2}$ & 0.88 & 2.08 & $2.920(8)$ & 160 \\
$(d)$ & $\mathrm{N}(22)-\mathrm{H}(22) \cdots \mathrm{O}(2)^{\# 3}$ & 0.88 & 2.07 & $2.913(8)$ & 160 \\
& $\mathrm{~N}(11)-\mathrm{H}(11) \cdots \mathrm{N}(1)$ & 0.88 & 2.72 & $3.263(9)$ & 121 \\
$(e)$ & $\mathrm{C}(35)-\mathrm{H}(35) \cdots \mathrm{O}(2)^{\# 4}$ & 1.08 & 2.37 & $3.178(9)$ & 130 \\
$(f)$ & $\mathrm{C}(36)-\mathrm{H}(36) \cdots \mathrm{O}(4)^{\# 5}$ & 1.08 & 2.38 & $3.170(9)$ & 129 \\
$(g)$ & $\mathrm{C}(22)-\mathrm{H}(22 \mathrm{~A}) \cdots \mathrm{O}(3)^{\# 6}$ & 1.08 & 2.46 & $3.267(9)$ & 131 \\
\hline
\end{tabular}

Table 5. Hydrogen bonds ( $\mathrm{A}, \mathrm{deg})$ for compound $\mathbf{1}$.

Symmetry transformations used to generate equivalent atoms: ${ }^{\# 1} x+1 / 2,-y+1 / 2, z$; $\# 2-x+1,-y, z+1 / 2 ; \quad \# 3-x+1 / 2, y+1 / 2, z+$ $1 / 2 ; \quad \# 4-x+1 / 2, y+1 / 2, z-1 / 2 ; \quad \# 5-x+$ $1 / 2, y-1 / 2, z-1 / 2$.

similar antiperiplanar conformations [torsion angles $-176^{\circ}(\mathbf{1})$ and $\left.166,-163,170,-163^{\circ}(3)\right]$, whereas the corresponding value in $\mathbf{2}$ is $72^{\circ}$.

A second degree of freedom is the planarity of the heterocyclic rings. This too varies from compound to compound, but in the previously determined structures the rings are in general approximately planar, with mean deviations $<0.1 \AA$ and absolute torsion angles $\leq 20^{\circ}$; this is also the case for the compounds $\mathbf{1}-\mathbf{3}$. Finally, the gold atoms are usually approximately coplanar with the rings (absolute $\mathrm{Au}-\mathrm{S}-\mathrm{C}-\mathrm{N}$ torsion angles close to zero); values here are $-4,9^{\circ}$ for $1,-21,-20^{\circ}$ for 2 and $1,-10,-10,5,-27,1,2,-6^{\circ}$ for 3 . In our previous publications we have noted that these degrees of flexibility, especially of the $\mathrm{C}-\mathrm{S} \cdots \mathrm{S}-\mathrm{C}$ torsion angle, make the cations less suitable for "crystal engineering" concepts, but the detailed analysis of the packing (see below) reveals instructive ways in which the cations adapt to their crystal environment.

None of the compounds $\mathbf{1 - 3}$ display short "aurophilic contacts" [9]; there are no Au $\cdots$ Au distances $<5 \AA$.

\section{Crystal packing: compound 1}

Compound 1 has four classical hydrogen bond donors (the four NH groups) and five potential acceptors (the anion $\mathrm{N}$ and four $\mathrm{O}$ atoms). Four two-centre hydrogen bonds (Table 5) are formed, whereby the acceptor N1 is not involved except as a possible weak component of an asymmetric three-centre interaction together with $\mathrm{H} 11 \cdots \mathrm{O} 3$. These bonds combine in a straightforward manner to form ribbons parallel to the $x$ axis (Fig. 4), in which the NH groups of neighbouring cations are bridged by $\mathrm{O}-\mathrm{S}-\mathrm{O}$ groups of the anions. Bonds $a$ and $b$ (for labels see Table 5) form a chain of graph set $C_{2}^{2}(8)$ [10], as do bonds $c$ and $d$. These oppositely directed chains combine to form the complete ribbon, whereby the $\mathrm{S}-\mathrm{Au}-\mathrm{S}$ moieties act as crosslinks to form rings of graph set $R_{4}^{4}(24)$. Within these rings, atom $\mathrm{O} 1$ approaches atoms $\mathrm{Au}$ and $\mathrm{S} 1$ to

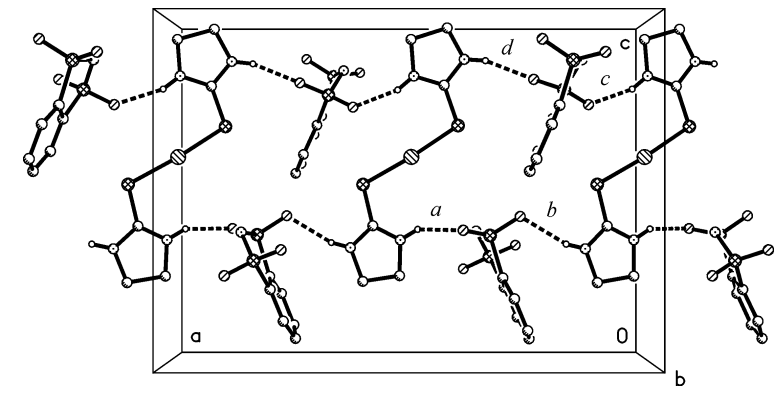

Fig. 4. Compound 1 , ribbon structure in the region $y \approx 1 / 4$ viewed parallel to the $y$ axis. Dashed lines represent classical hydrogen bonds. For labels see Table 5 .

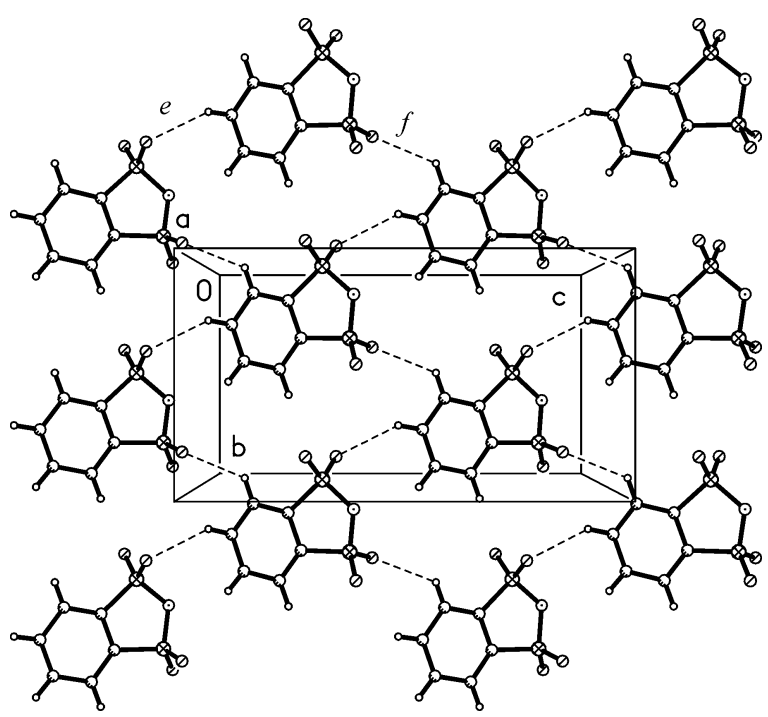

Fig. 5. Compound 1 , anion layer at $x \approx 1 / 4$ viewed parallel to the $x$ axis. Dashed lines represent classical hydrogen bonds. For labels see Table 5.

3.27 and $3.33 \AA$, respectively. Within any given ribbon, each anion only uses two oxygen acceptors; the other two then link to the next ribbons either above or below in the $y$ direction and thus lead to the overall three-dimensional packing.

There are three structurally significant $\mathrm{C}-\mathrm{H} \cdots \mathrm{O}$ interactions (although their angles are narrow). Two of 


\begin{tabular}{llcccc}
\hline & $\mathrm{D}-\mathrm{H} \cdots \mathrm{A}$ & $\mathrm{d}(\mathrm{D}-\mathrm{H})$ & $\mathrm{d}(\mathrm{H} \cdots \mathrm{A})$ & $\mathrm{d}(\mathrm{D} \cdots \mathrm{A})$ & $\angle(\mathrm{DHA})$ \\
\hline$(a)$ & $\mathrm{N}(12)-\mathrm{H}(12) \cdots \mathrm{N}(1)$ & $0.83(2)$ & $2.21(2)$ & $3.029(5)$ & $174(5)$ \\
$(b)$ & $\mathrm{N}(11)-\mathrm{H}(11) \cdots \mathrm{O}(3)^{\# 1}$ & $0.84(2)$ & $2.51(3)$ & $3.250(5)$ & $147(4)$ \\
$(c)$ & $\mathrm{N}(11)-\mathrm{H}(11) \cdots \mathrm{O}(1)^{\# 2}$ & $0.84(2)$ & $2.67(4)$ & $3.338(5)$ & $137(4)$ \\
$(d)$ & $\mathrm{N}(21)-\mathrm{H}(21) \cdots \mathrm{O}(3)^{\# 1}$ & $0.81(2)$ & $2.29(4)$ & $2.944(5)$ & $138(5)$ \\
$(e)$ & $\mathrm{N}(21)-\mathrm{H}(21) \cdots \mathrm{O}(1)^{\# 2}$ & $0.81(2)$ & $2.59(4)$ & $3.253(6)$ & $139(5)$ \\
$(f)$ & $\mathrm{N}(22)-\mathrm{H}(22) \cdots \mathrm{O}(4)^{\# 3}$ & $0.82(2)$ & $2.31(3)$ & $3.055(5)$ & $151(5)$ \\
$(g)$ & $\mathrm{N}(22)-\mathrm{H}(22) \cdots \mathrm{O}(2)^{\# 3}$ & $0.82(2)$ & $2.64(4)$ & $3.295(6)$ & $138(5)$ \\
$(h)$ & $\mathrm{N}(22)-\mathrm{H}(22) \cdots \mathrm{N}(1)^{\# 3}$ & $0.82(2)$ & $2.69(4)$ & $3.249(5)$ & $127(4)$ \\
$(i)$ & $\mathrm{C}(13)-\mathrm{H}(13 \mathrm{~B}) \cdots \mathrm{Au}$ & 1.08 & 2.63 & $3.680(4)$ & 163 \\
$(j)$ & $\mathrm{C}(22)-\mathrm{H}(22 \mathrm{~A}) \cdots \mathrm{Au}$ & 1.08 & 3.00 & $3.799(4)$ & 131 \\
$(k)$ & $\mathrm{C}(22)-\mathrm{H}(22 \mathrm{~A}) \cdots \mathrm{S}(1)^{\# 1}$ & 1.08 & 2.93 & $3.980(5)$ & 164 \\
$(l)$ & $\mathrm{C}(46)-\mathrm{H}(46) \cdots \mathrm{S}(1)$ & 1.08 & 2.74 & $3.790(5)$ & 164 \\
$(m)$ & $\mathrm{C}(33)-\mathrm{H}(33) \cdots \mathrm{S}(2)^{\# 5}$ & 1.08 & 2.82 & $3.761(5)$ & 146 \\
\hline
\end{tabular}

Table 6. Hydrogen bonds ( $\mathrm{A}, \mathrm{deg}$ ) for compound 2.

Symmetry transformations used to generate equivalent atoms: ${ }^{\# 1} x+1 / 2,-y+1 / 2, z+1 / 2$; \#2 $x-1 / 2,-y+1 / 2, z+1 / 2 ; \quad \# 3 \quad x, y, z+1$; \#4 $x-1 / 2,-y+1 / 2, z-1 / 2 ;$ \#5 $1-x, 1-y$, $1-z$. these, $e$ and $f$, combine to form anion layers [1] parallel to the $y z$ plane (Fig. 5), in which rings of graph set $R_{4}^{4}(21)$ may be recognised. In Fig. 4 , bond $f$ acts across the centre of the rings (but is not explicitly included), whereas bond $e$ links adjacent ribbons in the $x z$ plane. Bond $g$ links cations and anions of neighbouring layers.

Because the $\mathrm{S}-\mathrm{Au}-\mathrm{S}$ axes of the cations are sterically exposed, many short contacts of the form C$\mathrm{H} \cdots \mathrm{Au}$ and $\mathrm{C}-\mathrm{H} \cdots \mathrm{S}$ are observed. In previous structures and elsewhere in this paper, we have attributed hydrogen bonding properties to such interactions. In compound $\mathbf{1}$, they are mostly very long (H..Au $c a$. $3.3 \AA$ ) and probably do not influence the packing significantly. A complete list can be found in the Supplementary Material.

\section{Crystal packing: compound 2}

Compound 2 fulfils the same preconditions as compound 1 for hydrogen bonding; the cation is the same and the anion also has five potential hydrogen bond acceptors. Indeed, a layer structure is again formed (Fig. 6), but in this case the layers are not linked as in 1. However, the nature of the hydrogen bonding is completely different. Most surprisingly, there is only one simple two-centre classical hydrogen bond (entry $a$ in Table 6, also shown in Fig. 2) and this involves the anion nitrogen atom as acceptor. The other $\mathrm{N}-\mathrm{H}$ donors are involved in asymmetric three-centre (H11, $\mathrm{H} 21$ ) or four-centre (H22) hydrogen bonds to the anion $\mathrm{O}$ and $\mathrm{N}$ atoms; it is noteworthy that atoms $\mathrm{O} 1$ and $\mathrm{O} 2$ accept none of the shortest components of the multicentre $\mathrm{H}$ bonds, but only two or one weaker branches, respectively. In Fig. 6, only the shortest branches of each $\mathrm{H}$ bond system are included throughout the Figure; for clarity, the longer branches are shown only

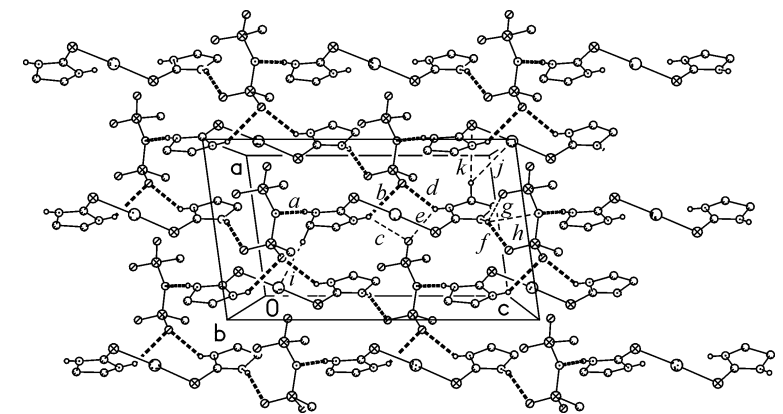

Fig. 6. Compound 2 , layer structure at $y \approx 1 / 4$ viewed parallel to the $y$ axis. Only the ipso $\mathrm{C}$ atoms of the anion rings are shown. Thick dashed lines represent short classical hydrogen bonds; thin dashed lines (for clarity only one of each type is shown) represent weaker interactions (see text). For labels see Table 6.

once each

The layers also involve one very short $(\mathrm{H} \cdots \mathrm{Au}$ $2.63 \AA$ A $\mathrm{C}-\mathrm{H} \cdots \mathrm{Au}(i)$ and a three-centre C-H $\cdots(\mathrm{S}, \mathrm{Au})$ interaction $(j, k)$. Again, each is included in Fig. 6 only once.

Because of the extensively multi-centre hydrogen bonding, graph set analysis is less meaningful. One easily recognisable feature is the $R_{2}^{2}(4)$ ring formed by $\mathrm{H}$ bonds $b-e$, right of centre in the unit cell (Fig. 6). The gold atom is positioned above this ring and makes a short contact of 3.375(3) $\AA$ to O3.

Because the chlorophenyl rings are omitted from Fig. 6 for clarity, some features involving these rings need extra explanation. These and other contacts can be recognised in the side view of adjacent layers (Fig. 7). There are two $\mathrm{C}-\mathrm{H} \cdots \mathrm{S}$ interactions $(l, m)$ and the contacts $\mathrm{Au} \cdots \mathrm{Cl} 2(1-x, 1-y$, $1-z) 3.414(2) \AA(n)$ and $\mathrm{S} 2 \cdots \mathrm{Cl} 1(1-x, 1-y, 1-z)$ $3.480(2) \AA(o)$, all within the layers. Between the layers, only a single contact, $\mathrm{Cl} 1 \cdots \mathrm{Cl} 23.655(2) \AA(p)$, is observed via the $x$ axis translation. With $\mathrm{C}-\mathrm{Cl} \cdots \mathrm{Cl}$ an- 


\begin{tabular}{llllll}
\hline & $\mathrm{D}-\mathrm{H} \cdots \mathrm{A}$ & $\mathrm{d}(\mathrm{D}-\mathrm{H})$ & $\mathrm{d}(\mathrm{H} \cdots \mathrm{A})$ & $\mathrm{d}(\mathrm{D} \cdots \mathrm{A})$ & $<(\mathrm{DHA})$ \\
\hline$(a)$ & $\mathrm{N}(12)-\mathrm{H}(12) \cdots \mathrm{O}(9)^{\# 2}$ & $0.83(2)$ & $2.05(4)$ & $2.859(12)$ & $165(12)$ \\
$(b)$ & $\mathrm{N}(21)-\mathrm{H}(21) \cdots \mathrm{O}(7)$ & $0.83(2)$ & $2.10(6)$ & $2.843(12)$ & $149(11)$ \\
$(c)$ & $\mathrm{N}(22)-\mathrm{H}(22) \cdots \mathrm{N}(4)$ & $0.83(2)$ & $2.15(4)$ & $2.940(14)$ & $160(11)$ \\
$(d)$ & $\mathrm{N}(31)-\mathrm{H}(31) \cdots \mathrm{O}(13)$ & $0.82(2)$ & $2.14(5)$ & $2.903(12)$ & $155(11)$ \\
$(e)$ & $\mathrm{N}(32)-\mathrm{H}(32) \cdots \mathrm{N}(2)$ & $0.83(2)$ & $2.27(6)$ & $3.003(13)$ & $147(10)$ \\
$(f)$ & $\mathrm{N}(41)-\mathrm{H}(41) \cdots \mathrm{O}(3)$ & 0.88 & 2.12 & $2.827(14)$ & 136 \\
$(g)$ & $\mathrm{N}(42)-\mathrm{H}(42) \cdots \mathrm{N}(1)^{\# 3}$ & $0.83(2)$ & $2.04(3)$ & $2.859(13)$ & $170(12)$ \\
$(h)$ & $\mathrm{N}(51)-\mathrm{H}(51) \cdots \mathrm{O}(6)^{\# 4}$ & 0.88 & 2.29 & $2.955(12)$ & 133 \\
$(i)$ & $\mathrm{N}(52)-\mathrm{H}(52) \cdots \mathrm{O}(14)^{\# 3}$ & $0.82(2)$ & $2.22(4)$ & $3.020(12)$ & $163(11)$ \\
$(j)$ & $\mathrm{N}(61)-\mathrm{H}(61) \cdots \mathrm{O}(11)^{\# 5}$ & $0.83(2)$ & $2.33(9)$ & $2.932(13)$ & $129(10)$ \\
$(k)$ & $\mathrm{N}(62)-\mathrm{H}(62) \cdots \mathrm{N}(3)^{\# 4}$ & $0.83(2)$ & $2.06(5)$ & $2.819(13)$ & $153(11)$ \\
$(l)$ & $\mathrm{N}(72)-\mathrm{H}(72) \cdots \mathrm{O}(1)^{\# 3}$ & $0.82(2)$ & $2.09(7)$ & $2.827(12)$ & $149(12)$ \\
$(m)$ & $\mathrm{N}(81)-\mathrm{H}(81) \cdots \mathrm{O}(16)^{\# 3}$ & $0.83(2)$ & $2.09(6)$ & $2.820(12)$ & $147(10)$ \\
$(n)$ & $\mathrm{N}(82)-\mathrm{H}(82) \cdots \mathrm{O}(8)^{\# 4}$ & $0.82(2)$ & $2.25(9)$ & $2.831(12)$ & $128(10)$ \\
$(o)$ & $\mathrm{N}(11)-\mathrm{H}(11) \cdots \mathrm{I}(1)^{\# 1}$ & 0.88 & 3.06 & $3.818(9)$ & 145 \\
& $\mathrm{~N}(11)-\mathrm{H}(11) \cdots \mathrm{I}(2) \# 1$ & 0.88 & 3.41 & $3.972(10)$ & 124 \\
$(p)$ & $\mathrm{N}(71)-\mathrm{H}(71) \cdots \mathrm{I}(5)$ & 0.88 & 3.01 & $3.830(10)$ & 156 \\
$(q)$ & $\mathrm{C}(43)-\mathrm{H}(43 \mathrm{~A}) \cdots \mathrm{Au}(2)^{\# 3}$ & 1.08 & 2.78 & $3.639(12)$ & 137 \\
$(r)$ & $\mathrm{C}(63)-\mathrm{H}(63 \mathrm{~A}) \cdots \mathrm{Au}(3)^{\# 6}$ & 1.08 & 2.81 & $3.831(13)$ & 158 \\
$(s)$ & $\mathrm{C}(33)-\mathrm{H}(33 \mathrm{~A}) \cdots \mathrm{Au}(1)$ & 1.08 & 2.66 & $3.641(14)$ & 152 \\
$(t)$ & $\mathrm{C}(53)-\mathrm{H}(53 \mathrm{~A}) \cdots \mathrm{Au}(4)$ & 1.08 & 2.72 & $3.760(13)$ & 161 \\
\hline & & & & &
\end{tabular}

Table 7. Hydrogen bonds ( $\mathrm{A}, \mathrm{deg}$ ) for compound $\mathbf{3}$.

Symmetry transformations used to generate equivalent atoms: \#1 $x, y-1, z$; $\# 2-x+1,-y,-z+1 ; \quad \# 3-x+1,-y+1,-z$; \#4 $-x+1,-y+1,-z+1 ; \quad \# 5 \quad x, y+1, z$; $\# 6-x+1,-y+2,-z+1$.

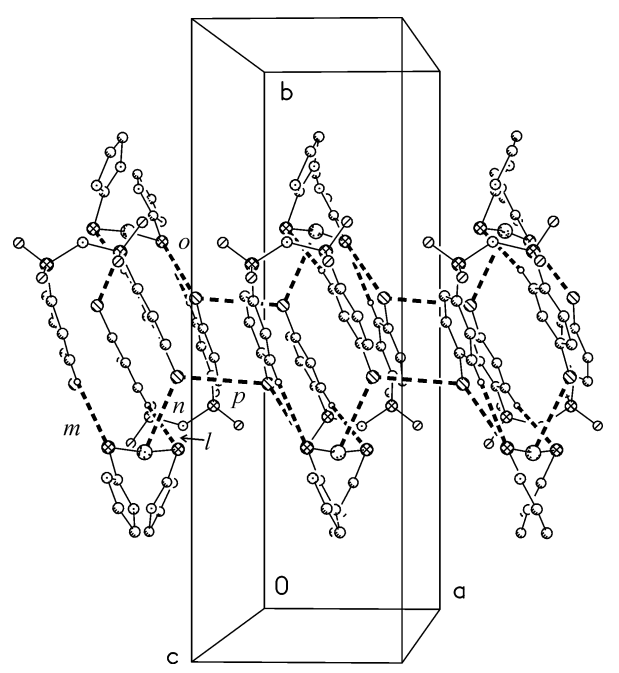

Fig. 7. Compound 2, three adjacent layers viewed edge on. Dashed lines represent various secondary interactions. For labels see Table 6 and text.

gles of 74.0 and $115.1(2)^{\circ}$, this may be classified as a "type I" interaction [11], which are not considered to arise from specific attractive forces.

\section{Crystal packing: compound $\mathbf{3}$}

Replacing the $p$-chloro substituent in $\mathbf{2}$ by $p$-iodo has a dramatic effect. Compound $\mathbf{3}$ crystallizes with four independent formula units and the packing is correspondingly complicated. Involvement in classical hydrogen bonds is restricted to 14 of the 16 potential

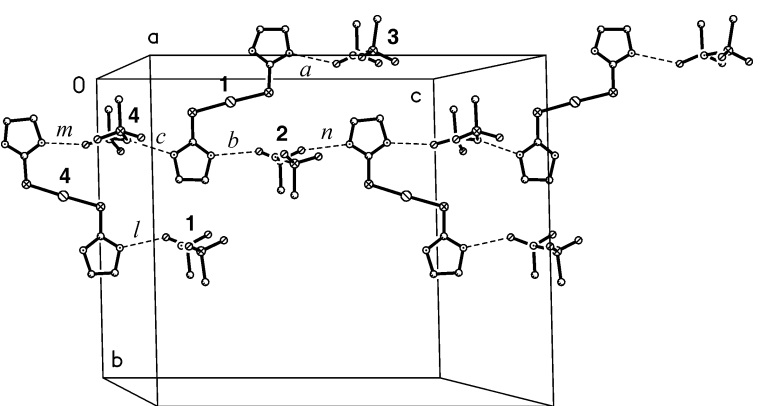

Fig. 8. Compound 3, chain formation parallel to the $z$ axis. Dashed lines represent classical hydrogen bonds. For italic labels see Table 7. Numbering of cations and anions refers to the $\mathrm{Au}$ and $\mathrm{N}$ atoms, respectively. Hydrogen atoms are omitted; $p$-iodophenyl rings are represented by the ipso carbon atoms.

NH donors and ten of the 16 potential oxygen acceptors (six ap and four $s c$ ); all four anion nitrogen atoms act as acceptors. All the classical $\mathrm{H}$ bonds are twocentre systems.

As is usual in complex three-dimensional packing systems, it is easier to split the structure into more easily assimilable parts. In this way, it can be seen that the anions play a mediating role between two substructures involving all anions together with cations 1 and 4 or 2 and 3 , respectively.

The cations 1 and 4 (based on the gold numbering) interact with the anions to form the first substructure, an alternating cation-anion chain parallel to the $z$ axis (Fig. 8). Within the chain, the hydrogen bonds $m, c, b, n$ (Table 7) combine to yield the graph set $C_{4}^{4}(16)$. The 


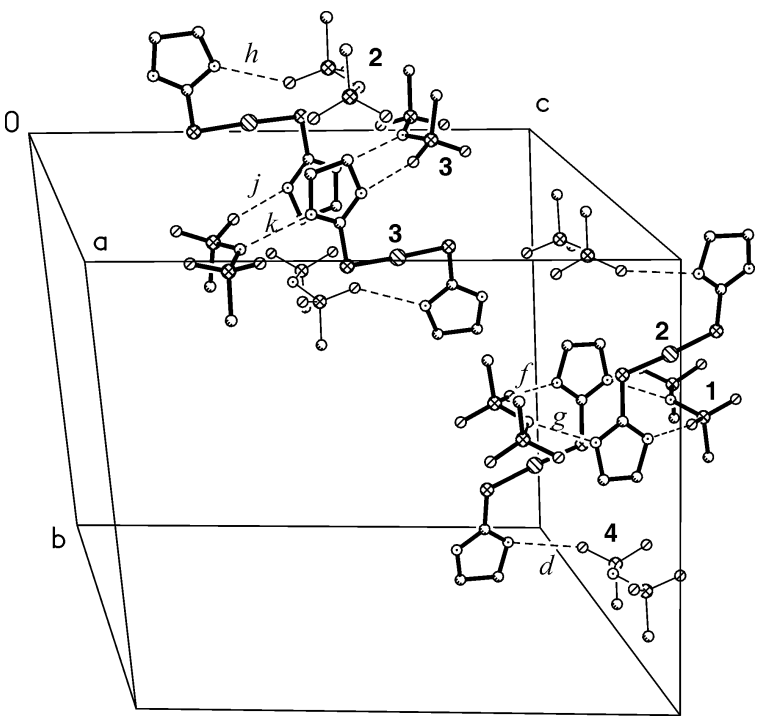

Fig. 9. Compound $\mathbf{3}$, cyclic dimer formation via $\mathrm{H}$ bonds (dashed lines). For italic labels see Table 7. Numbering of cations and anions refers to the $\mathrm{Au}$ and $\mathrm{N}$ atoms, respectively. Hydrogen atoms are omitted; $p$-iodophenyl rings are represented by the ipso carbon atoms.

bridging anions are not topologically equivalent, because anion 4 (based on the nitrogen numbering) is an N,O and anion 2 an O,O acceptor. The hydrogen bonds $a$ and $l$ branch off the main chain to anions 1 and 3 , which play a terminating role in this substructure (but connect to the second substructure).

Cation 2 combines with anion 1 (as an N,O acceptor) to form an inversion-symmetric, cyclic dimer of graph set $R_{4}^{4}(16)$ via $\mathrm{H}$ bonds $f$ and $g$; the $\mathrm{H}$ bond $d$ is formed exocyclically to anion 4 . An exactly analogous topology is shown by the dimer of cation 3 and anion 3, with anion 2 exocyclic ( $\mathrm{H}$ bonds $j, k, h$ ). These dimers, shown in Fig. 9, constitute the second substructure. The anions exert a pincer effect on the two cations that they connect; the short $\mathrm{C}-\mathrm{H} \cdots$ Au interactions $q$ and $r$ (not shown in Fig. 9) probably reinforce this effect across the dimers. The remaining two classical bonds $e$ and $i$ connect the dimers to each other (Fig. 10), whereas the remaining two $\mathrm{C}-\mathrm{H} \cdots \mathrm{Au}$ interactions $s$ and $t$ connect the two substructures (not shown).

Two NH donors $(\mathrm{H} 11, \mathrm{H} 71)$ remain that do not take part in classical hydrogen bonds. These form short contacts, which may reasonably be regarded as hydrogen bonds $(o, p)$, to iodine atoms. A closer inspection of the chains of Fig. 8 reveals the structural role of these contacts. The translation of the chain by

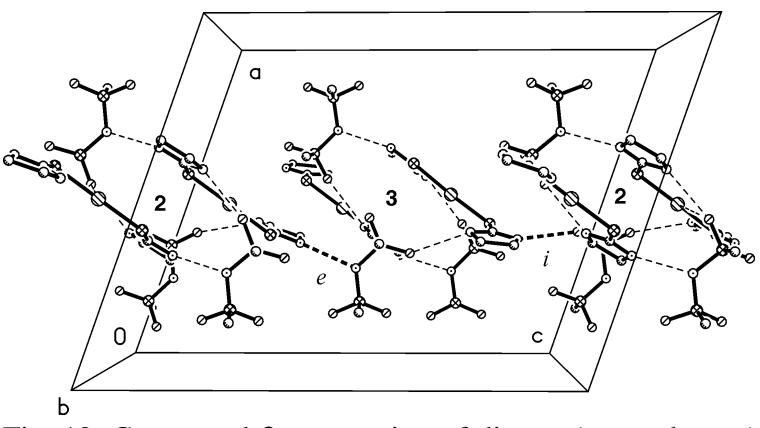

Fig. 10. Compound $\mathbf{3}$, connection of dimers (seen edge on) via $\mathrm{H}$ bonds (thick dashed lines). For italic labels see Table 7. Numbering of dimers refers to the Au atoms. Hydrogen atoms are omitted; $p$-iodophenyl rings are represented by the ipso carbon atoms.

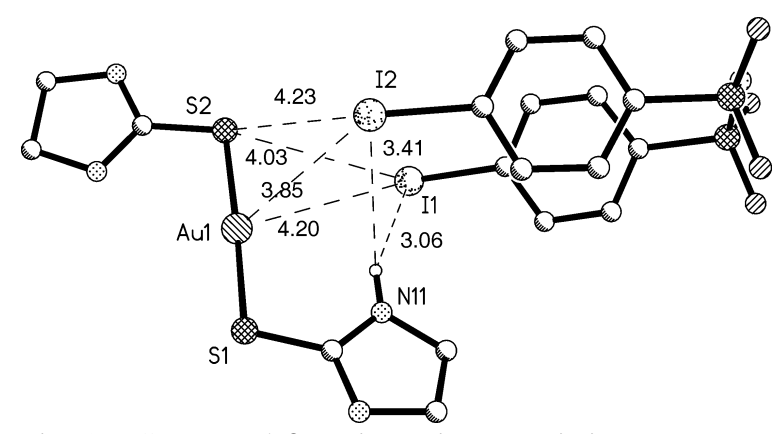

Fig. 11. Compound 3, cation-anion association via $\mathrm{Au} \cdots \mathrm{I}$ and $\mathrm{S} \cdots \mathrm{I}$ contacts and NH...I hydrogen bonds. Distances are in $\AA$.

$\Delta y=+1$ causes the narrow $\mathrm{S}-\mathrm{Au}-\mathrm{S}$ unit of cation 1 of the translated chain to lie between the ring iodines of anion 2, the ends of the "hairpin". This association is illustrated in more detail in Fig. 11, which shows the $\mathrm{H}$ bond $o$ together with the $\mathrm{S} \cdots \mathrm{Au}$ and S...I contacts. Although these are somewhat longer than the sum of the van der Waals radii, the overall effect of the contacts may well be to stabilize the system. A similar effect applies to cation 4 and anion 3 via $\Delta y=-1$; this may be additionally recognised in Fig. 3, in which however the contacts are not explicitly drawn.

In view of the structure-determining nature of the classical hydrogen bonds, we do not analyse a series of $\mathrm{C}-\mathrm{H} \cdots \mathrm{S}$ and $\mathrm{C}-\mathrm{H} \cdots \mathrm{I}$ interactions; for details, the Supplementary Material should be consulted.

\section{Conclusions}

Despite the apparently closely similar nature of the three compounds investigated, especially compounds $\mathbf{2}$ 
and $\mathbf{3}$, their hydrogen bonding patterns are completely different. Although the packing of compound 1 is conceptually simple (all $\mathrm{NH}$ groups act as donors and all anion $\mathrm{O}$ atoms as acceptors in two-centre $\mathrm{H}$ bonds), compound 2, for no obvious reason, instead exhibits several multi-centre $\mathrm{H}$ bond systems, and compound 3 crystallizes with four independent formula units. In both these compounds the anion nitrogen atoms function as $\mathrm{H}$ bond acceptors, while several potential oxygen acceptors are not utilised. This again demonstrates the resistance of the whole series of compounds to structure prediction or analogies based on chemical similarity; in other words to the concept of "crystal engineering".

\section{Experimental Section}

Physical measurements

These were recorded as described in [3].

\section{Preparations}

The compounds $\left[(\mathrm{etu})_{2} \mathrm{Au}\right]^{+} \mathrm{X}^{-}$were prepared from the corresponding chloride as follows: $1 \mathrm{mmol}\left[(\mathrm{etu})_{2} \mathrm{Au}\right]^{+} \mathrm{Cl}^{-}$ was dissolved in $50 \mathrm{~mL}$ of ethanol and treated with a solution of the silver disulfonylamide $\mathrm{AgX}$ ( $1 \mathrm{mmol}$; kindly provided by Prof. A. Blaschette) in acetonitrile $(5 \mathrm{~mL})$. The cloudy reaction mixture was stirred for $1.5 \mathrm{~h}$ at r. t. in the dark. After filtering off the precipitated $\mathrm{AgCl}$, the colourless filtrate was stored at $-18{ }^{\circ} \mathrm{C}$ for $12 \mathrm{~h}$ to yield crystals of the required products $\mathbf{1}-\mathbf{3}$.

Bis(imidazolidine-2-thione)gold(I) benzene-1,2-di(sulfonyl) amide (1)

Yield: $0.50 \mathrm{~g}(81 \%)$. Dec. $>187{ }^{\circ} \mathrm{C} .-{ }^{1} \mathrm{H}$ NMR $\left(\mathrm{d}_{6}-\mathrm{DMSO}\right): \delta=3.75\left(\mathrm{H}, \mathrm{s} ; \mathrm{CH}_{2}\right), 7.72\left(4 \mathrm{H}, \mathrm{m} ; \mathrm{H}_{\mathrm{Ar}}\right)$, $9.31(4 \mathrm{H}$, bs; $\mathrm{NH}) .-\mathrm{MS}$ (gly): FAB (neg.; $\mathrm{A}=$ anion) $\mathrm{m} / z=218\left(13 \%,[\mathrm{~A}]^{-}\right) ; \mathrm{FAB}$ (pos.; $\mathrm{K}=$ cation) $\mathrm{m} / \mathrm{z}=$ $401\left(100 \%,[\mathrm{~K}]^{+}\right) .-\mathrm{C}_{12} \mathrm{H}_{18} \mathrm{AuN}_{5} \mathrm{O}_{4} \mathrm{~S}_{4}$ (619.54): calcd. C 23.33, H 2.61, N 11.31, S 20.70; found C 23.60, H 2.74, N 11.40, S 20.60 .

\section{Bis(imidazolidine-2-thione)gold(I) di(4-chlorobenzenesulf- onyl)amide (2)}

Yield: $0.33 \mathrm{~g}(43 \%)$. Dec. $>176{ }^{\circ} \mathrm{C} .-{ }^{1} \mathrm{H}$ NMR $\left(\mathrm{d}_{6}-\right.$ DMSO): $\delta=3.76\left(8 \mathrm{H}, \mathrm{s} ; \mathrm{CH}_{2}\right), 7.44\left(4 \mathrm{H}, \mathrm{d},{ }^{3} J\left(\mathrm{H}_{\mathrm{m}}-\mathrm{H}_{\mathrm{o}}\right)=\right.$ $\left.8.7 \mathrm{~Hz} ; \mathrm{H}_{\mathrm{m}}\right), 7.64\left(4 \mathrm{H}, \mathrm{d} ; \mathrm{H}_{\mathrm{o}}\right), 9.31(4 \mathrm{H}, \mathrm{bs} ; \mathrm{NH}) .-\mathrm{MS}$ (NBA): FAB (neg.) $\mathrm{m} / z=364\left(100 \%,[\mathrm{~A}]^{-}\right.$); FAB (pos.) $\left.m / z=299\left(25 \%,\left[\mathrm{~K}-\mathrm{C}_{3} \mathrm{H}_{6} \mathrm{~N}_{2} \mathrm{~S}\right)\right]^{+}\right), 401\left(100 \%,[\mathrm{~K}]^{+}\right)$, $699\left(5 \%,\left[2 \mathrm{~K}-\left(\mathrm{C}_{3} \mathrm{H}_{6} \mathrm{~N}_{2} \mathrm{~S}\right)-\mathrm{H}\right]^{+}\right) .-\mathrm{C}_{18} \mathrm{H}_{20} \mathrm{AuCl}_{2} \mathrm{~N}_{5} \mathrm{O}_{4} \mathrm{~S}_{4}$ (766.54): calcd. C 28.20, H 2.64, N 9.14, Cl 9.25; found C 28.17, H 2.71, N 9.13, Cl 9.21.
Bis(imidazolidine-2-thione)gold(I) di(4-iodobenzenesulfonyl)amide (3)

Yield: $0.24 \mathrm{~g}(25 \%)$ - Dec. $>183{ }^{\circ} \mathrm{C} .-{ }^{1} \mathrm{H}$ NMR $\left(\mathrm{d}_{6}-\right.$ DMSO): $\delta=3.75\left(8 \mathrm{H}, \mathrm{s} ; \mathrm{CH}_{2}\right), 7.38\left(4 \mathrm{H}, \mathrm{d},{ }^{3} J\left(\mathrm{H}_{\mathrm{o}}-\mathrm{H}_{\mathrm{m}}\right)=\right.$ $\left.8.3 \mathrm{~Hz} ; \mathrm{H}_{\mathrm{o}}\right), 7.73\left(4 \mathrm{H}, \mathrm{d} ; \mathrm{H}_{\mathrm{m}}\right), 9.31(4 \mathrm{H}, \mathrm{bs} ; \mathrm{NH}) .-\mathrm{MS}$ (NBA): FAB (neg.) $\mathrm{m} / z=421\left(6 \%,[\mathrm{~A}-\mathrm{I}]^{-}\right), 547(100 \%$, $\left.[\mathrm{A}-\mathrm{H}]^{-}\right), 548\left(100 \%,[\mathrm{~A}]^{-}\right)$; FAB (pos.) $=299(20 \%$, $\left.\left[\mathrm{K}-\left(\mathrm{C}_{3} \mathrm{H}_{6} \mathrm{NS}_{2}\right)\right]^{+}\right), 401\left(100 \%,[\mathrm{~K}]^{+}\right), 402\left(12 \%,[\mathrm{~K}+\mathrm{H}]^{+}\right)$, $699\left(7 \%,\left[2 \mathrm{~K}-\left(\mathrm{C}_{3} \mathrm{H}_{6} \mathrm{NS}_{2}\right)-\mathrm{H}\right]^{+}\right) .-\mathrm{C}_{18} \mathrm{H}_{20} \mathrm{AuI}_{2} \mathrm{~N}_{5} \mathrm{O}_{4} \mathrm{~S}_{4}$ (949.44): calcd. C 22.77, H 2.13, N 7.38; found C 22.93, H 2.15, N 7.22.

\section{$X$-ray structure determinations}

The crystals were mounted in inert oil on glass fibres. Data were measured using Mo $K_{\alpha}$ radiation $(\lambda=0.71073 \AA)$ on Siemens P4 (2,3) or Bruker SMART 1000 CCD diffractometers (1), fitted with low temperature attachments. Structures were refined anisotropically on $F^{2}$ [12]. Crystal data and refinement details are presented in Table 1, selected molecular dimensions in Tables $2-4$, and hydrogen bond dimensions in Tables 5-7.

Hydrogen atom treatment: For 2, associated with its good crystal quality, hydrogen atoms bonded to nitrogen atoms were located in Fourier syntheses and refined freely, but with $\mathrm{N}-\mathrm{H}$ distances restrained to be equal using the SADI instruction [12]. For $\mathbf{1}$ and $\mathbf{3}$, the moderate crystal quality led to problems in locating the hydrogen atoms of the $\mathrm{NH}$ groups (these $\mathrm{H}$ atoms cannot be geometrically positioned with certainty because their parent nitrogen atoms cannot be assumed to have a planar substituent geometry). Some $\mathrm{H}$ atoms were located directly, some were placed geometrically assuming a planar geometry and then allowed to refine; those that were not stable were fixed at idealised planar geometry. The reliability of the $\mathrm{H}$ atom positions can be judged by their sensible hydrogen bonding interactions (see Discussion). Other hydrogen atoms were placed in calculated positions and refined using a riding model.

Special features of refinement: Compound 1 was refined as a racemic twin, with components $0.55: 0.45(1)$. For compounds $\mathbf{1}$ and $\mathbf{3}$, an extensive system of restraints (to displacement parameters, local ring symmetries and equivalence of independent molecules) was employed to improve refinement stability.

For the calculation of hydrogen bonding parameters, $\mathrm{C}-\mathrm{H}$ bond lengths were normalised to $1.08 \AA$ [13]. Contacts with uncorrected angles $<130^{\circ}$ at hydrogen have generally been omitted.

Complete crystallographic data (excluding structure factors) have been deposited at the Cambridge Crystallographic Data Centre under the numbers CCDC 681656 (1), 681657 (2) and 681658 (3). Copies may be obtained free of charge via www.ccdc.cam.ac.uk/data_request/cif. 
[1] Part 3: S. Friedrichs, P. G. Jones, Z. Naturforsch. 59b, 1429 (2004).

[2] This publication also represents Part CLXXVI of the series "Polysulfonylamines". Part CLXXV: O. Moers, A . Blaschette, V. Latorre, P. G. Jones, Z. Naturforsch. 61b, 923 (2006).

[3] S. Friedrichs, P. G. Jones, Z. Naturforsch. 59b, 49 (2004).

[4] S. Friedrichs, P. G. Jones, Z. Naturforsch. 59b, 793 (2004).

[5] O. Moers, S. Friedrichs, A. Blaschette. P. G. Jones, Z. Anorg. Allg. Chem. 628, 589 (2002).

[6] V. Lozano, O. Moers, P. G. Jones, A. Blaschette, Z. Naturforsch. 59b, 661 (2004).
[7] D. Henschel, T. Hamann, O. Moers, P.G. Jones, A. Blaschette, Z. Naturforsch. 60b, 645 (2005).

[8] E.-M. Zerbe, P. G. Jones, A. Blaschette, unpublished results.

[9] H. Schmidbaur, Gold Bull. 23, 11 (1990).

[10] J. Bernstein, R.E. Davis, L. Shimoni, N.-L. Chang, Angew. Chem. 107, 1689 (1995); Angew. Chem. Int. Ed. Engl. 34, 1555 (1995).

[11] V. R. Pedireddi, D. S. Reddy, B. S. Goud, D. C. Craig, A. D. Rae, G. R. Desiraju, J. Chem. Soc., Perkin Trans. 2, 2353 (1994).

[12] G. M. Sheldrick, SHELXL-97, Program for the Refinement of Crystal Structures, University of Göttingen, Göttingen (Germany) (1997).

[13] T. Steiner, Acta Cryst. B54, 456 (1998). 